\title{
A Study on the Relationships between Job Engagement of Middle School Teachers and Its Relative Variables
}

\author{
Ying Kong \\ School of Education Science \\ Qufu Normal University \\ E-mail: kongying1986@yeah.net
}

\begin{abstract}
The present paper, based on relative studies done both at home and abroad, intends to investigate the relationships between individual characteristics of middle school teachers and their job engagement. Methodology by using the UWES (Utreeht Work Engagement Scale) Result The relevance between middle school teachers' individual characteristics and the variables of job engagement is significant. The regression analysis further finds out that the regression is significant between middle school teachers' individual characteristics and the dimensions (vigor, dedication, and absorption) of job engagement. In addition, gender and length of teaching can predict the degree of teachers' engagement into teaching. Conclusion Teachers' individual characteristics studied in the present paper have an effect on their job engagement.
\end{abstract}

Keywords: Job engagement, Individual characteristics, Vigor, Dedication, Absorption

With the development of Positive Psychology and Positive Organizational Behavior, the long-ignored human virtues, such as the strength and positivity of the members in an organization, and positive mental abilities are attracting more and more attention. Within this context, job engagement, as the opposite of job disengagement, becomes the new research focus of scholars.

Kahn (1990) puts forward the concept of "personal engagement" for the first time. And he defines personal engagement as the harnessing of organization members' selves to their work roles (Kahn, 1990: 694). From the point of view of Kahn, self and work role exist in some dynamic and negotiable relation: when engaged deeper in his or her job, a person both drives personal energies into role behaviors (self-employment) and displays the self within the role (self-expression); in the opposite condition, the individual uncouples self from role, avoids creating job achievement, and displays an evacuation from role obligations. Scholars, such as Schaufeli, extend Kahn's concept of job engagement in another way. They define job engagement as a full state with persistent and positive moods and motivations, with vigor, dedication, and absorption as its major features.

Although the factor of human beings is becoming salient in the new social conditions, the research into job engagement of teachers is relatively few. It is of great significance to study the roles played by teachers' job engagement in the improvement of teachers' work, life quality and the full cultivation of teachers' potentiality. Such kind of research is also of importance to promote the healthy growing-up of students and to push the development of the education cause.

Based on studies done both at home and aboard, the present author attempts to investigate the effect of teachers' individual characteristics on their job engagement.

\section{Subjects and methods}

\subsection{Subjects}

The current study selected 300 teachers randomly from six middle schools to fill in the questionnaires. 259 questionnaires were recovered, reaching a response rate of $86 \%$. Among the six middle schools, three are located in the urban areas, and the other three are from the countryside. Of all the teachers, 149 were male ones, occupying $57.5 \%$; and 110 female teachers, with a percentage of $42.5 \%$. 


\subsection{Instruments}

The measurement of job engagement was conducted with the UWES (Utreeht work engagement scale), which was designed by Schaufeli. The scale involves three factors: vigor, dedication, and absorption. Zhang Yiwen, a scholar in China, has proved that the UWES deserves a high degree of reliability and validity among the group of teachers.

\subsection{Data analysis}

SPSS 11.5 was used for analyzing the data in the present study.

\section{Results}

\subsection{The differences in job engagement between middle school teachers with different characteristics}

First of all, a comparison was done to reveal the differences in job engagement between teachers with different characteristics. The compound analysis $(2 \times 2 \times 6)$ was used for analyzing the three factors: gender, marital status, and length of teaching (see Table 1).

Table 1 shows that the difference between male and female teachers in their job engagement is manifested mainly on the dimension of dedication. The interaction between gender and marital status has a significant difference in the dimensions of vigor and dedication of job engagement.

\subsection{The differences in job engagement between male and female middle school teachers}

A further investigation of the scores gained by male and female teachers in their job engagement shows that male teachers have higher scores over female ones on the dimension of vigor and absorption while female teachers gain more scores than male ones on the dimension of dedication.

\subsection{The differences in job engagement between middle school teachers with different marital status}

From the above analysis, it can be seen that the interaction between middle school teachers' gender and their marital status has a significant difference in the dimensions of vigor and dedication of job engagement. A further analysis of the scores gained by middle school teachers in their job engagement on the three dimensions shows: unmarried teachers have higher scores than those married ones on all the three dimensions of job engagement, esp. on the dimensions of vigor and dedication.

\subsection{The differences in job engagement between middle school teachers with different length of teaching}

A further analysis of the scores gained by middle school teachers of different length of teaching shows that middle school teachers with $0 \sim 5$ years of teaching gain the highest scores on all the three dimensions. However, there is a fall in the job engagement of teachers who have a length of $6 \sim 10$ years of teaching experience. And there is a rise in job engagement of teachers with 11 15 years of teaching. Teachers who have 16 20 years of teaching experience gain the lowest scores on the dimensions of dedication and absorption.

\section{Discussions}

The results of the present study show that there exist differences in job engagement between male and female teachers in middle schools, esp. on the dimension of dedication. Female teachers value more their jobs than male ones. In other words, the characteristics of patience, full of love, and carefulness make female teachers gain higher scores than male ones in job engagement on the dimension of dedication. Male teachers gain higher scores on the dimensions of vigor and absorption than female ones, which can be partly explained by the fact that men are generally more vigorous than women. Meanwhile, it is not a bad job of being a middle school teacher for male teachers, for such kind of job can satisfy their sense of achievement, which makes them more absorbed.

Unmarried teachers gain higher scores than married teachers on all the three dimensions, which may be explained by the fact that unmarried teachers have more time and energy to spend on the education job. Generally speaking, due to having a short time in teaching, male teachers feel refreshed when they work, and this will strengthen their engagement in teaching.

Teachers with a length of teaching for $0 \sim 5$ years gain higher scores than those in other groups in job engagement on all the three dimensions. Usually, the teachers who have just begun teaching have a fresh feeling towards their job, and are full of energy. In addition, the job of being a middle school teacher both for both men and women can be recognized by the society. There appears a fall in job engagement of teachers with a length of teaching for $6 \sim 10$ years. The two possible reasons: one is that they feel a bit tired after a period of high-engagement into teaching; another reason is that teachers in this group have established their own families, which makes them distribute part of their energy into their families. Thus, it is understandable that there appears a fall in their job engagement. Then, a rise appears in job engagement of the teachers. On the whole, after 6 years of teaching, there will appear a fall-rise curve in the job engagement of middle school teachers. 


\section{Conclusions and Implications}

Through the analysis of the job engagement of 259 teachers from six middle schools, the present study draws the following conclusions:

(1) Female teachers dedicate significantly more than male teachers in their job engagement. The education departments should on the one hand make effective use of the characteristics of female teachers as being patient, full of love and careful; on the other hand they ought to strengthen the efficient management of male teachers, create reasonable atmosphere and conditions for them, make them involved in education job and experience success and happiness, thus to make them more devoted into teaching.

(2) The strength of unmarried teachers' full of energy and deep engagement into teaching should be made good use of. The teaching tasks should be assigned reasonably. Efforts should be made to create a harmonious human relationships and a good cultural atmosphere at school. In addition, the job engagement of married teachers should be strengthened.

(3) High pertinence should be strengthened according to the different length of teaching of the teachers. The construction of school culture should be favorable for relieving the tiredness and pressure of teaching for the teachers, so as to make them more dedicated into teaching. Thus, the healthy growing-up of students in middle schools can be effectively promoted and further the development of the education cause can be pushed ahead.

(Soft-science Project in Shandong Province: research on the improvement of the competition competence of High-tech leading enterprises in Shandong. Project Number: 2008RKA198)

\section{References}

Kahn, WA. (1990). Psychological Conditions of Personal Engagement and Disengagement at Work. Academy of Management Journal, 33(4): 692 724.

Li Jin-bo, Xu Bai-hua, \& Chen Jian-ming. (2006). The Effect of Organizational Factors on Job Engagement. Chinese Journal of Applied Psychology, 12(2): 176 181.

Li, Rui \& LING, Wen. (2007). A Review of the Research on Work/Job Engagement. Advances in Psychological Science, 15 (2): 366 372.

Saleh, S. D. \& Hosek, J. (1976). Job involvement: Concept and measurement. Academy of Management Journal, 19(2): 213 224.

Schaufeli, W. B., Salanova M, Gonza RV, et al. (2002). The Measurement of Engagement and Burn Out: A Confirmative Analytic Approach. Journal of Happiness Studies, 3(1): 71 92.

Sheng, Jian-sen. (2006). Teachers, Job Involvement: Its Structure and Influencing Factors. Psychological Development and Education, (2): 108 112.

Zhang Yi-wen \& GAN Yi-qun. (2005). The Chinese Version of Utrecht Work Engagement Scale: An Examination of Reliability and Validity. Chinese Journal of Clinical Psychology, 13(3): 268 271.

Table 1. The compound analysis of the job engagement of middle school teachers with different gender, marital status and length of teaching

\begin{tabular}{lccc}
\hline Source of variance & vigor & dedication & absorption \\
\hline gender & 1.251 & $4.138^{*}$ & 1.225 \\
marital status & 0.299 & 0.028 & 0.005 \\
length of teaching & 0.305 & 0.561 & 1.225 \\
gender $\times$ marital status & $4.099^{*}$ & $5.300^{*}$ & 2.691 \\
gender $\times$ marital status & 1.373 & 2.087 & 2.156 \\
marital status $\times$ length of teaching & 0.431 & 0.617 & 1.099 \\
gender $\times$ marital status $\times$ length of teaching 0.796 & 0.384 & 0.013
\end{tabular}

Notes: " $\times$ " stands for the interaction; ${ }^{*} p<0.05$ 
Table 2. A comparison of job engagement between male and female teachers

\begin{tabular}{lcc}
\hline & Male teachers M(SD) & Female teachers M(SD) \\
\hline vigor & $29.08(6.82)$ & $27.96(6.96)$ \\
dedication & $24.94(6.84)$ & $25.35(6.26)$ \\
absorption & $25.28(5.70)$ & $25.16(5.58)$ \\
\hline
\end{tabular}

Table 3. A comparison of job engagement between teachers of different marital status

\begin{tabular}{lcc}
\hline & Unmarried teachers M(SD) & Married teachers M(SD) \\
\hline vigor & $29.55(7.40)$ & $28.40(6.77)$ \\
dedication & $25.77(6.43)$ & $24.97(6.63)$ \\
absorption & $25.38(5.19)$ & $25.20(5.75)$ \\
\hline
\end{tabular}

Table 4. A comparison of job engagement between teachers of different length of teaching

\begin{tabular}{lcll}
\hline & vigor M(SD) & dedication M(SD) & absorption M(SD) \\
\hline 0-5 years (group1) & $30.00(6.22)$ & $26.58(5.89)$ & $26.02(5.25)$ \\
6-10 years (group2) & $27.84(7.50)$ & $24.48(7.17)$ & $25.03(5.92)$ \\
$11-15$ years(group 3) & $28.28(6.53)$ & $25.46(6.52)$ & $25.26(.29)$ \\
$16-20$ years(group 4) & $28.31(7.55)$ & $23.69(6.21)$ & $24.25(6.73)$ \\
$21-25$ years(group 5) & $29.00(6.10)$ & $24.42(7.40)$ & $25.53(6.26)$ \\
over 25 years(group 6) & $28.57(7.41)$ & $25.14(6.43)$ & $25.07(4.94)$ \\
\hline
\end{tabular}

